\title{
THE F.M. HOYT SHOE COMPANY: A HISTORICAL VIEW OF PRODUCTION AND MANAGEMENT ACCOUNTING IN AN EARLY 1900s REGIONAL MANUFACTURER
}

ABSTRACT: The city of Manchester, New Hampshire, was famously known as the home of the Amoskeag Manufacturing Company, one of the country's largest manufacturers of textiles and other products. But over the duration of about one hundred years, Manchester was also the site of more than seventy different shoe companies. Although nearby Massachusetts was a true hub of shoe and boot production in the cities of Lynn, Haverhill, and Worcester, Manchester attracted its share of shoe manufacturers due to several key factors, and the city eventually hosted some of the largest shoe companies of that time. Recent archival discoveries provide a view into the production processes, management accounting, and financial activity of the F.M. Hoyt Shoe Company, one of the largest shoe companies located in Manchester from 1893-1930s.

In 1913, the state of New Hampshire ranked fourth nationally in total shoe production, behind the states of Massachusetts, New York, and Missouri. By 1920, the value of shoes and footwear manufactured in New Hampshire had exceeded $\$ 89,400,000$, with total wages paid of over $\$ 12,500,000$. As for Manchester, New Hampshire’s largest city, shoe and boot manufacturing was the city's second largest industry by 1920 , employing a total of 8,255 people, of whom 5,279 were male $(64 \%)$ and 2,976 were female $(36 \%)$.

The old shoe companies are long gone from Manchester, as well as many other locations in the United States. Within Manchester, with a present-day population of 110,000, several of these former sites are now re-purposed into condominiums, office property, and retail outlets. Visiting these locations prompts a nostalgic reflection of bustling production activity, including long hours of labor in hot or cold factories, and immigrant workers speaking in their native languages. Archival records exist in varying amounts for these former shoe companies. The bulk of historical information at the Manchester Historic Association was found on the three largest operations: the F.M. Hoyt Shoe Company, the W.H. McElwain Corporation (which would later become the International Shoe Company), and the J.F. McElwain Corporation. This paper 
focuses on the F.M. Hoyt Shoe Company, along with some of its manufacturing processes, cost accounting, and segment reporting.

With a 110-foot yellow brick chimney, the building now known as the Twin Towers Condominiums at 470 Silver Street was once the center of a busy shoe factory cluster named the F.M. Hoyt Shoe Company. The original factory building on Silver Street expanded to include two long wings, a supplementary manufacturing space on an adjacent property, and a thenmodern administration building on the corner of Lincoln and Silver Streets. At its peak size in 1917 , the company occupied a total area of over 239,000 square feet. It was initially the largest shoe factory in the city, and later the second largest after the McElwain Shoe Company was established. The building was listed into the National Register of Historic Places in 1985 after a rigid application process, due to its architectural significance and historical relevance to the city of Manchester. Today, in visiting this area in East Manchester, one can travel back in time to imagine the realities of shoe-making at its peak within the city.

The story of the F.M. Hoyt Shoe Company begins in 1842 with the birth of Francis Moody Hoyt on a Danville, New Hampshire farm, the only son of Nathan and Sally (Hook) Hoyt. He attended Kingston Academy and later went to school in Northfield, New Hampshire. Early endeavors included coopering, which he practiced until age 16, and then teaching school, which he later said enabled him to "handle hundreds of workmen". At age 19, like many young men of that time, he decided to pursue industrial apprenticeship in the shoe shops of Haverhill, Massachusetts, at the time, one of the largest sites of shoe and slipper production in the country. 


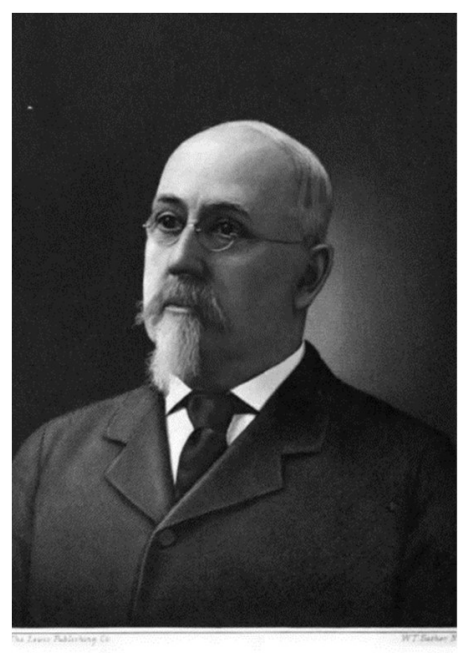

$$
\text { fuAort }
$$

Photo of Francis M. Hoyt, Public domain.

In 1866, Francis Hoyt married Eliza Ann Meserve of Freedom, New Hampshire, and their daughter Luella was born in 1876. Hoyt worked hard in the Haverhill shops and gained skills in all departments of the shoe factories, from cutting to selling, as well as supervising the stitching area. It was said "his name was famous as that of a skilled manufacturer of unimpeachable integrity”. By 1880, Hoyt was operating his own slipper shop in Haverhill, until it perished in the massive 1882 fire that destroyed much of the city's mill section. After this disaster, the family moved to Raymond, New Hampshire, in 1884, where Hoyt and his partner, John R. Towle, built a large factory to manufacture shoes, the firm named Hoyt and Towle. At its peak, this factory produced over 1,200 pairs of shoes per day. There are conflicting reports of why the company left the Raymond facility. Some believe the factory had reached full capacity and growth was impossible, while others say the building was significantly damaged during a fire in 1892 . Whichever the case, Hoyt chose Manchester as his next place of business.

Around this time, several coinciding issues occurred that accelerated capital investment in shoe production throughout the state. These factors included newly legislated tax exemptions, a 
growing immigrant population looking for work, and mechanical advancements in machinery for shoe and leather production. The first of these occurrences took place in the 1880 s when a statelegislated amendment to the New Hampshire Constitution allowed towns to vote on a tax exemption for a "term not over ten years on any manufacturing establishment proposed to be erected or put in operation therein: and the capital to be used in operating the same...”. Local investors took advantage of this opportunity and were inspired to create land and building companies to build and lease modern factory buildings. Not all the new companies opted for the tax exemption, but many of them did.

Next, an increasing wave of immigrants continued to flow into New England, including Manchester. Many immigrants had already arrived in Manchester to work at the Amoskeag Manufacturing Company, with a prevalence of Irish migration by the 1860s. Soon thereafter in the 1870s, immigrants arrived from many countries, including Germany, Scotland, Greece, Sweden, and Poland. However, the massive wave of immigrants from Quebec, Canada, with its convenient rail access to Manchester, had the greatest impact on the labor pool in the city, despite their inability to speak English. By 1895, the estimate of French-Canadians in Manchester, or their descendants, exceeded 17,000. Within fifteen years, the French-Canadians made up 35 percent of the city's population, many having settled in "Petit Canada" on Manchester's west side.

The third factor that accelerated the growth of the shoe industry in Manchester, as well as throughout New England and beyond, was the advancement of shoe and leather production equipment. Most of the innovations in shoe manufacturing equipment occurred in Massachusetts around the time of the Civil War. Massachusetts became a leader in shoe production, due to the significant concentration of shoe machinery companies and shoe factories around the Boston area. Prior to these mechanization advancements, shoes were tediously made by hand. This 
changed with the invention of the sewing machine by Elias Howe in the 1850s. While initially invented for sewing clothing, the machine was adapted as a dry-thread machine to do light upper-stitching of shoes, then further enhanced as a waxed-thread machine that allowed sewing of heavier upper leathers. Other equipment of note included the sole-cutting machine, the buttonhole machine, the automatic pegging machine, and the leather-sewing machine.

The invention of the McKay sole-sewing machine had the greatest impact on the shoe industry. Invented by Lyman Blake, a technician at the Singer Sewing Machine Company, this specialized machine sewed the soles to the upper portion of the shoes in approximately thirty seconds. Compared to the old pegging method, the McKay machine significantly lowered the cost of production. Blake sold his invention to Civil War Colonel Gordon McKay and together they innovated the machine to produce shoes for women, men, and children. The machine was immensely popular and shoes made on these machines were simply called McKays or McKay Welt shoes (a variation) for many years thereafter. Later in 1875, another popular machine produced by Charles Goodyear, Jr. enabled shoes to be sewn without penetrating to the inside, known as "turn" shoes. These popular machines considerably reduced the cost to make shoes and boots, and printed shoe advertisements used the common terms "welt", "turn", "Goodyear" and "McKay" to define their shoes, including the ads from F.M. Hoyt Shoe Company.

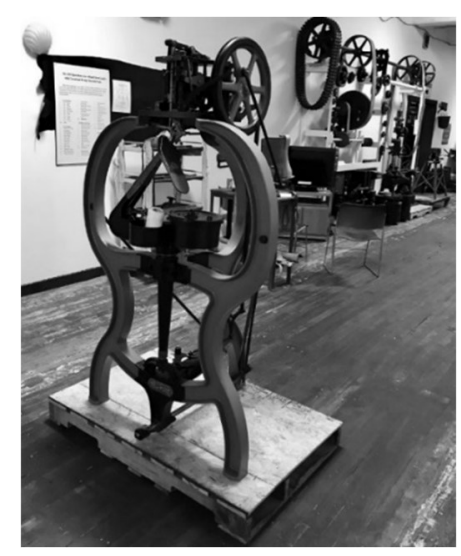

A Blake-McKay stitching machine. 


\section{Used with permission of Charles Williams.}

Given these three factors, the incentives were in place for entrepreneurs to set up shoe companies in Manchester. In 1890, the formation of the Queen City Land and Improvement Company occurred, and they purchased 60 acres of land in the southern part of Manchester. A six-acre parcel of that land was leased to the Queen City Manufacturing Company, which was incorporated in 1891 with $\$ 50,000$ capital provided by F.M. Hoyt, his wife Eliza A. Hoyt, and George Greeley (Hoyt's general manager from the Raymond plant). The remaining part of the 60-acre tract was eventually sold for housing. By 1900, many new homes were built in this "Hallsville" area, and a viable labor pool was created.

The first Hoyt factory was constructed in 1892 at a cost of $\$ 30,000$ along a line of the Portsmouth Railroad. With its flush brick walls, multi-paned windows set in arched masonry with granite sills, and a grand slate-roofed five-story stair tower, it was the largest-size shoe factory in New Hampshire at the time. The main building measured 43 feet x 220 feet, along with the tower, a 28 - by 35 -foot office annex, and a 40 - by 35 -foot boiler house. The building had automatic sprinklers, a valuable feature given the regular occurrence of fires in the mills, and machinery operation and heating were steam-powered with electricity available from the building's own dynamos.

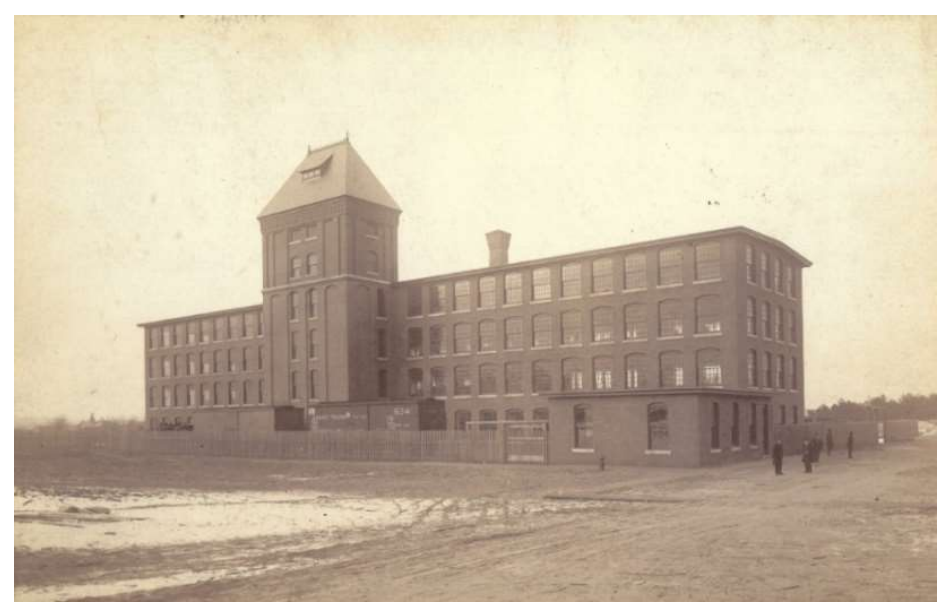


Image of first F.M. Hoyt Shoe factory on Silver Street in 1892. Manchester Historic Association.

Shoe production began in 1893, and the F.M. Hoyt Shoe Company employed approximately 300 people, making about 2,400 pairs of men's and boys' McKay shoes per day. The 1894 economic recession, traditionally regarded as the most severe cyclical downturn in the $19^{\text {th }}$ century history of the United States, occurred soon thereafter, causing a decline in shoe demand. Production costs increased at the same time, due to lower consumer demand for meat, which reduced the amount of leather and skins available for shoe production. The impact was most severe in smaller towns where small shoe companies failed, as they could not afford the costlier materials and the expensive leases and royalties of the McKay and Goodyear Welt machinesnor could they find mechanics to repair them. Thus, the larger, urban factories such as the F.M. Hoyt Shoe Company, which had capital to access the latest machinery and skilled labor, gained advantage.

F.M. Hoyt manufactured brands that included Hoyt's Amoskeag, Hoyt's Byron, Hoyt's Slayton, and the Hoyt's Custom Shoes in men's and boys' sizes. The Beacon Shoe and trademark began in 1902, and the company soon employed around 700, making it the one of the largest local employers. In July 1902, Hoyt implemented shoes sales directly through retail outlets, a practice which was uncommon at the time and closely watched by other manufacturers in the shoe industry. Fortunately, all went well, and the company's output increased, causing the need for overtime. Mr. Hoyt was quoted at this time as saying:

For twenty-five years I have made shoes commencing from the bottom. I have built my business up to its great volume of today by using plenty of sole leather. It is the best agent I ever had and today my hope of making 10,000 pairs of shoes a day is based on my judgment that merchants who have bought my shoes will recognize and appreciate this. I am going to do my business with progressive merchants and I shall spare no cost to meet their requirements. I have secured thirty of the most intelligent salesmen I could procure to show Hoyt's shoes to the trade. I have associated with me in every department the best men I could secure. On these lines I am expecting to win the confidence of the shoe merchants of the entire country. 
A few years previously, in June of 1900, Luella Hoyt, daughter of Francis and Eliza Hoyt, married local merchant Hovey E. Slayton. Shortly thereafter, Mr. Slayton joined the F.M. Hoyt Company, reporting to his father-in-law. With the famous Beacon trademark adopted, the company compiled a group of over 30 salesmen to sell directly to the retail trade from "Texas to the Dakotas, up to the coast of Maine". In 1903, however, Mr. F. M. Hoyt died suddenly at 61 years old. Mr. Hovey Slayton became President of the company and remained in that position for many years thereafter.

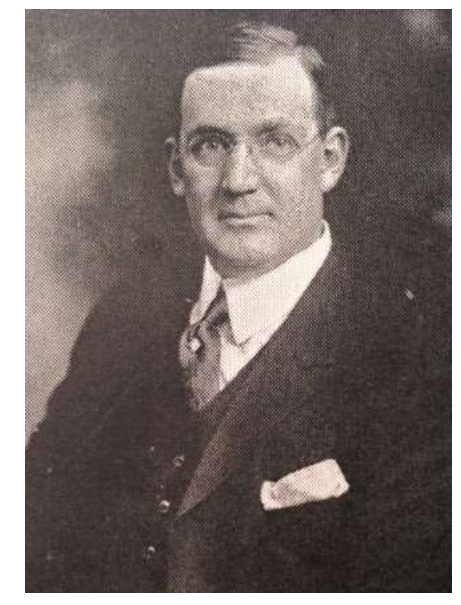

\footnotetext{
Photo of Hovey E. Slayton, President of F.M. Hoyt Shoe Company. Sales Manual of F.M. Hoyt Sales Manual, Manchester Historic Association.
}

Business thrived, and additions were made to the first building, almost tripling the floor space. This vast expansion added needed manufacturing space to the company and these additions carefully matched the original structure and allowed an increase in production to over 30,000 pairs of shoes per week. A second building was erected directly across the street, a mirror image of the first building, and then leased to the Eureka Manufacturing Company. This company hired 350 employees, and made medium-grade men's, boys' and youths' shoes. With 
steady growth, the F.M. Hoyt Shoe Company needed even more factory space, and in 1914, they took over the Eureka building to gain an additional 41,000 square feet of manufacturing space. A smaller building adjacent to the first factory was also built, along with corporate housing around that same area.

Momentum from the First World War in 1916 increased orders for military footwear from European governments, as happened at many other large shoe manufacturers. The old Eureka building was used to make large quantities of boots for the Russian Army. The building expanded, and the company was then capitalized at $\$ 750,000$, a considerable sum at that time. When the United States entered the conflict in April 1917, Hoyt added two more additional floors to the old Eureka building to manufacture Ordnance equipment such as leggings, pistol holders, gun slings, and canteen covers, while space was used in the first two buildings to manufacture shoes for the Army and Navy. During this time, over 22 different articles were made for the Ordnance, Navy, and Quartermaster Departments, and in July, 1918, a report to the U.S. government stated that 2,092 employees worked for the company, with 636 employees dedicated to fulfilling government orders. During these years, on June 12, 1917, the F.M. Hoyt Shoe Company became a million-dollar corporation, but with the war's end in November, 1918, all Ordnance orders ceased.

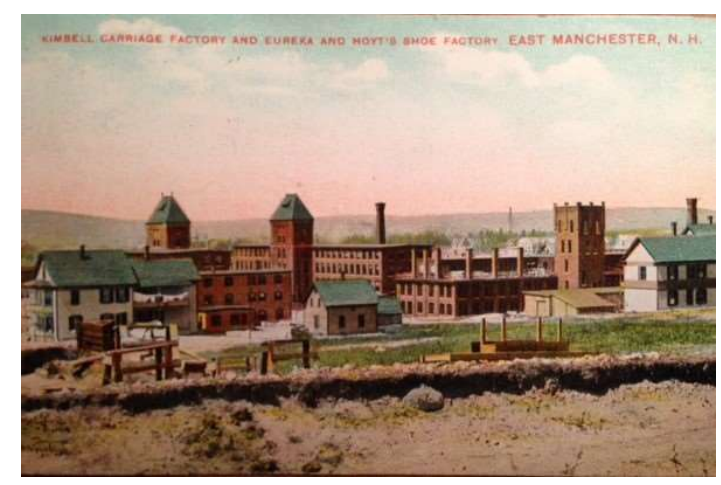

Early postcard view of FM Hoyt Shoe Company circa 1900. Collection of Yvette Lazdowski. 
Detailed information regarding the day-to-day operations of the F.M Hoyt Shoe Company was provided in a 135-page Sales Manual written by the officers and sales executives of the company in 1920. This archival treasure offers an in-depth look into the peak years of the Hoyt Company. While initially written as a book of guidance and company policies for the salesmen's use, it contains a wide array of information about shoe production, ordering and billing procedures, management practices, and production costs, along with selling advice, and sales data. Pie charts, histograms, and statistical data fill several pages, and are rather impressive since they were created without the use of modern office technology. Sales and segment reports were heavily analyzed by geographic location, product line, and manufacturing costs.

[Insert segment reports examples here]

In addition to the company statistics and segment reports, the manufacturing processes of the company's famous Beacon Shoe were extensively detailed in the 1920 Sales Manual. Raw materials usage, such as different hides and skins, depended upon the type and part of the shoe. For example, leathers used for the upper part of the shoe included kid, calfskin, cowhide, sheepskin, and horsehide. Sheepskin was the best material for linings and other parts of the shoe where there was less wear, while cowhide was preferred for the sides of the uppers, and heavy cattle hide used for the soles. The best of the heaviest hides came from animals who lived in warmer climates, as they would have thick and tough skin, yet thinner hair; hides from Texas were the first choice, followed by those from South America.

Quality tanning was crucial in conversion of hides or skins into leather, as it would ultimately affect the look, wear, and fit of the shoe. There were various types of tanning processes commonly used during this period, including oak, hemlock, union (a combination of oak and hemlock), chrome, and mongrel. All of these involved the use of an acidic procedure that 
"toughened" the hide, kept it from rotting, and helped remove any remaining animal hair. F.M. Hoyt received their leathers already tanned from their suppliers, thus tanning was included in raw material cost.

In addition to the details of sales, production volumes, product costs and financial results, the 1920 Sales Manual contains specifics of the manufacturing process that took place within the first F.M. Hoyt building. Shown below is a summary of these processes from the initial receipt of raw materials through the shipping of the finished product. A detailed plot plan from 1915 also shows where the various departments were located within the building:

UPPER LEATHER DEPARTMENT: In this area on the first floor of the main part of the building, the leather was received and sorted into matching shades, colors and textures. Tanning of the leather produced different effects, colors, and thicknesses, and great care was taken to look at every incoming piece of leather to ensure that shoe pairs matched perfectly. Around 1920, Hoyt used about 7,000,000 feet of leather annually, and it was a major cost component of the product.

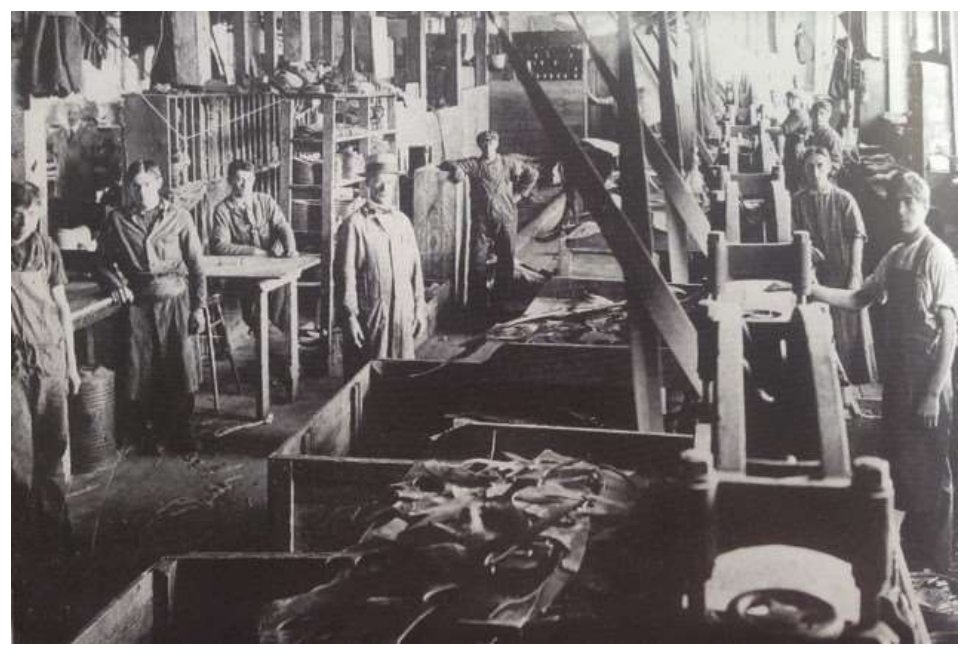

Workers inside FM Hoyt Shoe Company (1908). Manchester Visual History Collection, Gary Samson. 
CUTTING DEPARTMENT: This department was located on the fourth floor (highest floor) of the north wing. Here the leather was cut by hand or with a die for the upper parts of the shoe. A machine was used for the die cutting, one skin at a time. The vamp, which is the lower part of the upper portion of the shoe that gets attached to the sole, was taken from the best of the skin, since it would take more wear. The vamp and edges of the upper leather were beveled to a thin edge to give a more finished appearance. Girls and women usually performed this part of the job. Then the different parts of the uppers were assembled to be sent out for stitching.

STITCHING DEPARTMENT: The stitching department was located on the fourth floor of the west wing. The linings, trimmings, and all of the outer parts of the upper shoe were stitched via machinery. This department mostly employed women, although the heavier stitching was done by men. In addition to stitching, the shoe was cemented, fitted, and stained, and eyelets were inserted for the laces. Stitching involved close-up work, and was often located on the highest floor of a factory to maximize the use of natural light from the windows.

LINING DEPARTMENT: The linings were cut on a "dinking" machine, up to a dozen pairs at one time. The linings were used to reinforce the leather uppers and gave the shoe a good appearance. This department also made shoe covers to keep the shoes from getting soiled when moving through the factory. The plot plan does not show the specific site of the lining department, but this process may have been part of the fitting department located on the fourth floor of the main factory area.

LASTING DEPARTMENT: Located on the first floor of the north wing, the shoe lasting area was quite busy. This is where workers shaped the leather over wooden or metal molds. The lasts were in the precise measurements and proportions of the human foot, and "picked" from a bin. The insole was lightly tacked to the bottom of the last, then the shoe upper was placed over the 
last, pulled down firmly, and tacked. Machinery was used for this process, in which the outsole was applied, and the loose tacks were removed. Properly lasted shoes were pulled down well to remove the stretch from the leather. The leather was kept on the lasts from ten days to three weeks to dry and take the appropriate shape of the shoe. Properly sized lasts were essential to provide consistency and quality to shoe production, and having sufficient lasts of a particular size and style for the incoming sales orders was often a challenge.

INNERSOLE AND HEELING DEPARTMENT: Found on the third floor of the main part of the factory, this is where the innersoles were cut to specific sizes and went through a welt method that attached the sole to its under-surface using the Goodyear channeling machine. The heels started with leather that was "skived" through a machine to ensure even thickness, then rolled to make them firm. A heel builder placed the leather in piles for the specific height of the heel needed, then glued the pile of leathers together, and subsequently drove a nail through the pile for durability. The leather pile was put into a compressing machine that molded it into the desired shape as needed for the particular style and size of shoe.

WELTING DEPARTMENT: The third floor of the north wing is where this important production step took place. The welt was a narrow strip of leather that was first sewn to the lip of the innersole and to the upper leather, then later to the outer sole. This differed from the McKay method, where the stitching passed entirely through to the bottom of the shoe. The welt extended from the front of the heel all the way around the shoe. The entire process of welting involved using cement and then stitching the outsole to the welt using the Goodyear outsole lockstitch machine. The shoes made under this process were called "welt shoes", and it was considered the best method of making medium- to high-grade shoes. It was a skilled process which involved both machinery and precise handwork. 
MAKING DEPARTMENT: This department may also have been part of the fitting area on the fourth floor of the main building. Trimming machines were used to smooth away the roughness from the shoes, and the edges and welts of the shoe were blackened. A heeling machine was used to drive a nail through the heel, outsole, upper leather and innersole, which was then clinched on the inside, leaving enough nail protruding to attach the top lift (a piece of hardened leather). This blind nailing process attached the piece of leather on the outside of the heel that the customer would look at when inspecting a shoe, thus it was important to be done precisely.

FINISHING DEPARTMENT: Located on the second floor within the main factory building and also in the west wing, this department was where shoes went through the final processes of buffing, dusting, and staining the bottom sole. A coat of gum was applied on the stained sole and brushed to a polish. The top of the shoe was waxed and polished to a high luster in a friction roll. The shoes were inspected and the lasts were pulled from the shoes. A final inspection for tacks or nails on the inside of the shoe occurred before the shoes were stamped with the trademark or monogram.

TREEING AND PACKING DEPARTMENT: On the second floor of the north wing, the process of treeing the shoes made them conform perfectly to the shape of the last. It also restored the finish that belonged to each particular leather, and the workers used brushes specific to the type of leather in the shoe to remove dirt or other adhered materials. Different cleaners were also used based on the type of leather involved. The shoe was then carefully ironed to give it a perfect and permanent form. Lacing occurred next, after which the shoe was embossed with the dealer's name or brand. After final inspection, the shoes were packaged in descriptive cartons and shipped.. 


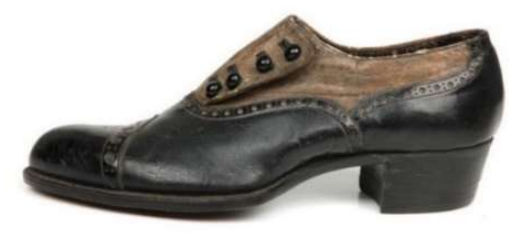

Image of Beacon Shoe. Used with permission from Nazim Mustafaev at shoe-icons.com.

The 1920 Sales Manual included the cost breakdown for making several different styles of men's shoes. Each shoe style included a similar cost sheet breaking down the raw materials, direct labor, and manufacturing overhead amounts. The manual discussed management's use of the cost sheets to strategize their sales and geographic concentration of particular shoe lines. An example of a cost sheet for the C Grade High Shoe is illustrated here:

Table 1: Cost to Produce the Men's C Grade High Shoe

Materials:

Cloth Lining \& Doublers

.0514

Stays \& Facings

.0685

Outsole

.2000

Insole

.0700

Welt

.0440

Counter

.0160

Heel

.0550

Hooks

.0240

Eyelets

.0087

Box Toes

.0200

Shank

.0060

Heel Pods

.0080

Lace

.0100

Total Materials

.5816

Direct Labor:

Cutting, Outsides, Lining

.0485

Lining \& Trimming

.0132

Stitching

.0792

Sole Leather

.0154

Lasting

.0616 


\begin{tabular}{ll} 
Bottoming & .0880 \\
Finishing & .0132 \\
Treeing and Packing & .0330 \\
Shipping & $\frac{.0179}{.3700}$ \\
Total Direct Labor & \\
\multicolumn{1}{c}{ Allocated Fixed Costs: } \\
Factory Overhead & .3000 \\
Royalty & .0800 \\
Findings (incidental and accessories) & .0800 \\
Lasts, Dies, \& Patterns & .0300 \\
Cases \& Cartons & .0500 \\
Total Allocated Fixed Costs & .5400 \\
& \\
Total Factory Costs & 1.4916
\end{tabular}

[Insert photo images of other cost sheets here]

Factory and working conditions fell under the area of the Employment and Service Department. A resident nurse and visiting doctor attended to employees in a daily clinic within the Medical Department. The visiting physician oversaw the air, light, and heat, as well as sanitary conditions, in tandem with the master mechanic. Long before the days of the Occupational Safety and Health Administration, the F.M. Hoyt Shoe Company, like many other factories, monitored their own safety concerns. The company's Safety Organization included both the Executive and Workmen's Committees, which together oversaw factory safety and carefully watched for accident hazards. Monthly inspection reports were reviewed by the Executive Committee. The Hoyt factory was a closed shop, and wage or hour disputes were settled in arbitration per the union contract, although the company stated that their pay rates were as high as those at other local shoe shops. The F.M. Hoyt Shoe Company took pride in their employees and their brand of Beacon shoes. 
For many years, sales remained robust, as shown in the 1920 Sales Manual. After the First World War, foreign representatives traveled overseas to establish accounts. The Beacon shoes were distributed through more than 10,000 agencies in the United States by its traveling salesmen and through direct representatives in countries around the world, including England, France, Belgium, Holland, Norway, Sweden, Denmark, Switzerland, Italy, Greece, Czechoslovakia, South Africa, the Philippines, Cuba, Mexico, Hawaii, India, China, and into the Far East. The company had sales offices in Boston, New York City, Philadelphia, Chicago, San Francisco, Mexico City, and Havana, Cuba. Retail stores, known as the Beacon Shoe Stores, operated by a subsidiary branch of the F.M. Hoyt Shoe Company. In 1920, the company acquired a factory in Haverhill, Massachusetts, known as Hilliard and Tabor, Inc., to begin production of a women's Beacon shoe line. The company anticipated that total production would increase to 12,500 pairs daily, with annual sales of $\$ 12,000,000$, and a capitalization of $\$ 3,000,000$. Sales had indeed increased significantly since 1903:

Table 2: Amount of Sales in Dollars Per Year, 1903-1920

$\begin{array}{rrrl}\text { 1903: } & 947,859 & 1912: & 2,033,952 \\ \text { 1904: } & 994,633 & 1913: & 2,648,184 \\ \text { 1905: } & 1,148,212 & 1914: & 2,440,204 \\ \text { 1906: } & 1,065,438 & 1915: & 2,525,931 \\ \text { 1907: } & 954,287 & 1916: & 4,031,897 \\ \text { 1908: } & 989,310 & 1917: & 5,591,081 \\ \text { 1909: } & 1,230,960 & 1918: & 4,106,122 \\ \text { 1910: } & 1,446,102 & 1919: & 5,455,400 \\ 1911: & 1,695,137 & 1920: & 5,045,400 \text { (first half of year only) }\end{array}$

Total Sales 1903 to first half of 1920: $\quad \$ 44,350,109$

Like the other shoe manufacturers of the time, F.M. Hoyt was well represented during the major retail shoe buying months of January and July. According to the Boot and Shoe Recorder, merchants would place orders in the central market of Boston, which was "at its best during the 
middle weeks of January". Two Boston hotels - Hotel Essex and the United States Hotel- were the primary locations for permanent sample rooms, representing over 400 shoe manufacturers. The F.M. Hoyt Shoe Company's sample room was located at the Hotel Essex, and they also established a leased sales headquarters in a corner suite at 60 South Street in Boston.

Sales were carefully recorded as to region, season, and salesman. Head of the Sales Promotion department, C.W. Jenks, included several motivating articles in the 1920 Sales Manual to help salesmen increase their efficiency and strategize their deals with merchants. The company advertised heavily in a variety of venues, including newspapers, magazines, trade journals, window displays, handbills, and on billboards and painted signs. One particular favorite outlet was the Saturday Evening Post, where the company had a specific advertising page for many years, and regular ads were posted in the leading weekly trade journal, the Shoe and Boot Recorder. A typical Beacon Shoe ad promoted the value and price of the Beacon Shoe, as seen in the McClure's Magazine advertisement below.

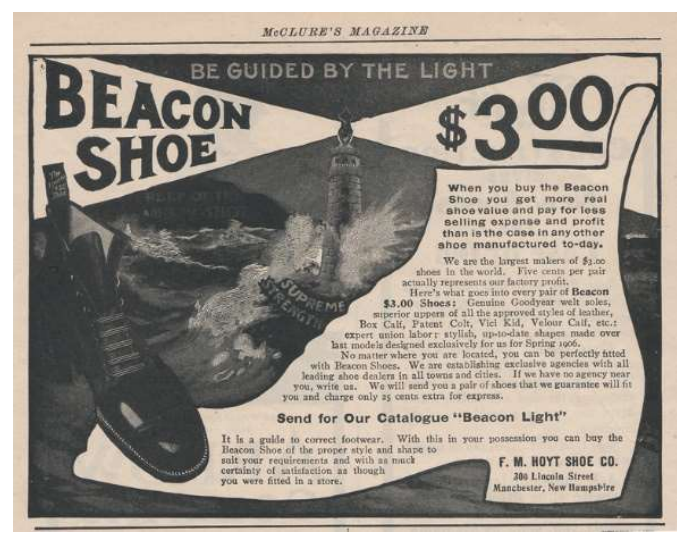

Beacon Shoes advertisement in McClure's Magazine. Used with permission from Nazim Mustafaev at shoe-icons.com. 
Always looking to increase sales, the company carefully monitored the shoe industry, including national and regional competitors. In 1920, it listed the daily production capacity of pairs of shoes by state, listing the top four states as Massachusetts (587,553 pairs), New York (295,570 pairs), Missouri (201,050 pairs), and New Hampshire (118,581). As the selling price of the Beacon shoes rose throughout the years, the increasing prices of raw materials, labor, and overhead were carefully watched. These concerns were typical for all shoe manufacturers. For example, the records in the 1920 Sales Manual indicated the rising trend of labor costs:

Table 3: Amount of Factory Payroll 1913-1920

Fiscal Year June to May

$\begin{array}{rr}\text { 1913-1914: } & \$ 538,548 \\ \text { 1914-1915: } & 549,280 \\ \text { 1915-1916: } & 605,962 \\ \text { 1916-1917: } & 1,027,222 \\ \text { 1917-1918: } & 1,194,488 \\ \text { 1918-1919: } & 1,084,857 \\ \text { 1919-1920: } & \underline{1,419,484}\end{array}$

Total Payroll, 1913-1920: \$6,419,841

The cost of materials was scrutinized as well — a finished pair of shoes in 1908 cost the company $\$ 2.384$, compared to a cost of $\$ 8.026$ in 1919 , an increase of 236 percent. While nearly all parts of the shoe were more expensive, the major culprit was the cost of the upper stock, as leather prices continued to rise. From 1908 to 1919, the price of leather for the upper stock rose from $\$ .60$ per shoe to $\$ 4.057$, an increase of 576 percent. Some of this occurred because of changing shoe styles, which included the addition of a women's line of dress shoes. However, escalating costs for materials and labor created pressure to increase the selling price of all the shoe lines. 
In 1919, the F.M. Hoyt Shoe Company built a new administration building on the southeast corner of Silver and Lincoln Streets, diagonally opposite the original factory. Prior to 1919, the administrative offices were located in a corner annex attached to the original building. The need for more office space paralleled the growth of the company, but there is little detail in the 1920 Sales Manual about the interior or use of the administrative building.

The years rolled by for the F.M. Hoyt Shoe Company, and they struggled to remain profitable. While the acquisition of Hilliard and Tabor, Inc., the company anticipated daily production of 12,500 pairs of shoes and annual sales of $\$ 12,000,000$. However, it is unknown if these goals were ever met. One record indicates that at their peak, the F.M. Hoyt Shoe Company produced over 9,600 pairs of shoes per day, employed 1,400 workers, and reported over $\$ 4,000,000$ in sales per year. Like most of the shoe manufacturers at the time, the company was plagued with higher costs and increased competition—locally by the McElwain Company, which in many ways was more progressive in minimizing the cost of its manufacturing processes through efficiencies and Taylorism practices.

Limited information was found about the Hoyt Company after 1920, but one newspaper article dated January 23, 1929, mentions a vote from the F.M. Hoyt members of the local Boot and Shoe Workers Union on accepting a wage reduction to avoid the company's closure. Per the article:

All the workers are voting the second time due to some illegality of the voting. Gen. John D. Murphy, treasurer and general manager of the company, stated today that he would be able to make a definite announcement on the wage subject Saturday morning. He was confident that he would have the results of the meetings by that time. Regarding the report that the Hoyt factory would close down permanently if the employees did not accept the wage reduction, General Murphy stated, 'the wages was only a small part of it. You have got to have the business in order to keep a plant going,' he added. In the meantime, the Hoyt factory is operating as usual, with all the employees at their work. 
Mr. Hovey Slayton died in 1938, and while the F.M. Hoyt Shoe Company survived into the 1930s, it never returned to its previous level of prosperity. Effects of the Great Depression swept throughout the country, and its impact was far-reaching on many industries, including shoe manufacturing. Ultimately, many struggling shoe companies went out of business. Evidence from a series of lawsuits dated 1941 to 1942 offers some clues of the company's slow demise. By that time, John D. Murphy was president of F.M. Hoyt, and the company had fallen into financial despair, having borrowed $\$ 112,500$ from the Reconstruction Finance Company (RFC) in 1934, and eventually was foreclosed upon by the RFC. Prior to this, in 1936, Hoyt had ceased manufacturing and then leased its previous production space to other shoe and non-shoe manufacturers. Lease payments were deposited in a suspended credit account at the Federal Reserve Bank of Boston, with the understanding that all maintenance expenses of the plant would be paid from that account, and the remaining balance would cover principal and interest owed to the Reconstruction Finance Company (RFC). The lawsuit involved overtime pay from October 1, 1940, through June 21, 1942, for a watchman, fireman, and maintenance man within the buildings, who claimed they had not been paid by the F.M. Hoyt Shoe Company nor the RFC. Upon appeal, the court found that F.M. Hoyt was responsible for payment of the overtime. However, there is no evidence that indicates whether the F.M. Hoyt Shoe Company ever paid the three workers for their overtime and court costs.

Perhaps this was the breaking point for the company, as by 1942, the F.M. Hoyt Shoe Company no longer existed as a shoe manufacturer in the city records. Over the years, the buildings were purchased or leased by a variety of shoe companies and manufacturers and the once proud administration building on the corner of Silver and Lincoln Streets had been taken over by the federal government during the Depression years to house the local WPA (Works Progress Administration) office. Later, it was used as the city's Armed Forces Induction Center. 
The onset of urban renewal in the 1970s and 1980s drew attention to the former F.M. Hoyt Shoe Company buildings. To avoid the possibility of razing the buildings, an application for recognition into the National Register of Historic Places took place in 1985. The owners and preservationist consultant provided valuable information about the construction and layout of these impressive buildings, along with the plans to give new life to the property as condominiums. On November 7, 1985, the F.M. Hoyt Shoe Company buildings were successfully listed in the National Register of Historic Places.

When looking at the old factory buildings today, it is hard to imagine the impact of the millions of pairs of shoes produced here and sold throughout the world, as well as the hardworking laborers who proudly made the Beacon Shoes. Without the 1920 Sales Manual recently donated to the Manchester Historic Association, as well as the detailed application to the National Register of Historic Places, few details would be known about the operations and financial records of this once-vibrant company that we can now appreciate as a jewel of Manchester's industrial past. Perhaps it is most telling to include the opening quote in the F.M. Hoyt Shoe Company 1920 Sales Manual:

He who sleeps beneath the fruit tree must be contented with the wind-falls; the one who climbs the ladder plucks the choicest fruit. 


\section{REFERENCES}

Baer, Thomas. Manchester Shoe Manufacturing, January 1996, Thomas Baer Collection, Manchester Historic

Association.

Biographical Sketches of Representative Citizens of the State of New Hampshire. New England Historical

Publishing Company.

Eaton, Aurore. The Amoskeag Manufacturing Company: A History of Enterprise on the Merrimack River.

Charleston, SC: The History Press, 2015.

Eichengreen, Barry and Steven Maddox. The Impact of Unions in the 1890's: The Case of the New Hampshire Shoe

Industry. UC Berkeley: Institute for Research on Labor and Employment, 1989.

First Biennial Report of the Bureau of Labor of the State of New Hampshire. Concord: Edward N. Pearson, Public

Printer, 1896.

Gannon, Fred A. A Short History of American Shoemaking. Salem, MA: Newcomb \& Gauss Printers,

1912.

Genealogical and Family History of the State of New Hampshire: A Record of Achievements of Her People in the

Making of a Commonwealth and the Founding of a Nation. New York: Lewis Publishing Company, 1908.

Hareven, Tamara and Randolph Langenbach. Amoskeag: Life and Work in an American

Factory-City. Lebanon,

NH: University Press of New England, 1978.

Hengen, Elizabeth. National Register of Historic Places Inventory-Nomination Form. United States Department of the Interior, National Park Service, 1985.

Jenks, C.W. The History of the F.M. Hoyt Shoe Company. Sales Manual of the F.M. Hoyt Shoe Company, 1920, Manchester Historic Association.

Perreault, Robert, B. Franco-American Life \& Culture in Manchester New Hampshire: Vivre La Difference.

Charleston, SC: The History Press, 2010. 
Rosenbloom, Joshua L. The Challenges of Economic Maturity: New England, 1880-1940.

Cambridge, MA: National

Bureau of Economic Research, 1999.

Taylor, Fredrick W. The Principles of Scientific Management. Norwood, MA: The Plimpton Press, 1911.

Thirteenth Biennial Report of the Bureau of Labor for the Fiscal Period Ending August 31, 1920. Bristol, NH:

Musgrove Printing House, 1920.

Thomson, Ross. The Path to Mechanized Shoe Production in the United States. Chapel Hill, NC: The University of North Carolina Press, 1989.

United States Department of Labor. A Survey of the Shoe Industry in New Hampshire. 